\title{
Knowledge, attitude, and practice toward the daily management of PICC in critically ill cancer patients discharged from intensive care units
}

This article was published in the following Dove Press journal: Cancer Management and Research

\author{
Jie Chen ${ }^{1,2, *}$ \\ Hui Zhao ${ }^{3, *}$ \\ Zhijie $\mathrm{Xia}^{3}$ \\ Ying Zhang' \\ Xiang Lv' \\ Xuhui Zhou' \\ Xiang Dong' \\ Jingjie $\mathrm{Li}^{\prime}$ \\ Hong Jiang' \\ Yan Huang' \\ Huimin Huang'
}

'Department of Anesthesiology, Shanghai 9th People's Hospital,

Shanghai Jiao Tong University School of Medicine, Shanghai, China; ${ }^{2}$ National Tissue Engineering Center of China, Shanghai, China; ${ }^{3}$ Department of Emergency, Huashan Hospital North, Fudan University School of Medicine, Shanghai, China

*These authors contributed equally to this work
Correspondence: Huimin Huang; Yan Huang

Department of Anesthesiology, Shanghai 9th People's Hospital, 639 Zhi Zao Ju Road, Shanghai 2000II, China $\mathrm{Tel} / \mathrm{Fax}+86212327$ 1699; ext 5170 Email eagle_zhangl19@163.com; jenney_chen0806@I63.com
Background: Peripherally inserted central catheters (PICCs) are widely used in critically ill cancer patients. We aimed to investigate the status of knowledge, attitude, and practice (KAP) toward the daily management of PICCs in critically ill cancer patients discharged from intensive care units.

Methods: Totally, 152 critically ill cancer patients discharged from two intensive care units in China were surveyed using a self-administered KAP questionnaire. Patients' demographics and PICC-related KAP scores were collected and analyzed using independent-samples $t$-test and multivariate stepwise linear regression analysis.

Results: All 152 patients completed the survey. The mean KAP scores were $32.61 \pm 3.80$ points, $28.11 \pm 3.18$ points, and $44.31 \pm 3.98$ points, respectively. KAP scores were found to have significant positive correlations with each other $(P<0.05)$. The major factors influencing the total KAP score were the PICC indwelling time and the patient's educational degree, age, and place of residence $(P<0.05)$.

Conclusion: We noted that KAP status toward the daily management of PICC in critically ill cancer patients discharged from intensive care units is not optimistic and needs to be further improved. Attention should be paid to the health education patterns of KAP, and individualized instruction should be pursued.

Keywords: malignant tumor, peripherally inserted central catheter, knowledge, attitude and practice, critically ill, intensive care unit

\section{Introduction}

Peripherally inserted central catheters (PICCs) provide an effective venous channel for chemotherapy in patients with malignant tumors. PICC is superior to other indwelling needles in reducing the stimulation of drugs on blood vessels, drug extravasation, and the pain of repeated puncture. Moreover, PICCs have a longer indwelling time, which can significantly improve the patients' quality of life. ${ }^{1-3}$ Compared to a central venous catheter, a PICC is easy to use and safe to manipulate, resulting in less severe complications. ${ }^{4-6}$ However, as a foreign body introduced into blood vessels, complications may occur because of improper operation, incorrect tip placement, mismanagement, or delayed maintenance. ${ }^{7-9}$ It has been reported that complications are possible throughout the entire indwelling period, with an overall incidence rate of $30 \%-40 \%$. The incidence rate in the first month of indwelling is high, but it decreases after the fifth week. Common complications include infections, phlebitis, tube blockage, effusion of blood or fluids, broken catheter, or exfoliation. 
The higher incidence of complications among malignant tumor patients may be associated with the following factors. First, there was close association between hypercoagulability and thrombus, with the incidence of thrombus in tumor patients being 4-7 times higher than that in nontumor patients. ${ }^{10}$ Second, chemotherapeutic drugs not only weaken immunocompetence, which could lead to infection, but also cause thrombus. ${ }^{11}$ Third, inadequate daily management of PICCs may correlate with patients' physiologic and psychological states, the side effects of chemotherapy, and patients' age, among others. Fourth, patients with indwelling PICCs are required to stay at home because of the long chemotherapy intermission. However, it appears that the incidence of complications is higher when care is provided at home rather than at a hospital. ${ }^{12}$ Thus, the prevention of PICC-related complications is a priority and challenge for nursing.

KAP for PICC daily management refers to the knowledge, attitude, and practice of patients regarding the prevention and reduction of PICC-related complications. Catheter management in daily life includes the recognition of any problems, the handling of exceptions, patient confidence, and observation of the tube and membrane application and of the movements of the PICC in the indwelling arm, but it does not include catheter maintenance (i.e., dressing changes, tube blowing). Few studies have investigated the direct effect of KAP on PICC daily management among cancer patients. In this study, a survey on the current status and impact of KAP on PICC daily management was administered with the goal of implementing proper nursing measurements based on influential factors likely to improve patients' daily management ability and to decrease the incidence of PICC-related complications.

\section{Methods \\ Subjects}

A survey questionnaire was conducted among malignant tumor patients selected by convenience sampling at two intensive care units (ICUs) in China from January to December 2016. The surveys were conducted within the 3 months of the patients' discharge from ICUs. Written informed consent to participate in this survey was obtained from all patients, and the use of related clinical materials was approved by institutional ethics committees of Shanghai 9th People's Hospital and Huashan Hospital North, and this study was performed in accordance with the Helsinki Declaration on ethical principles for medical research involving human subjects. Patients who met the inclusion criteria were 1) volunteered to participate in this study and provided a signed informed consent form; 2) had clear consciousness and self-care ability without communication barriers; 3) had been diagnosed with malignant tumors; 4) underwent the PICC tube procedure; 5) had the literacy and ability to work with the investigators. The following were the exclusion criteria for patients with malignant tumors: 1) patients who had cognitive disorder or other major illness; 2) patients who were unwilling to participating in this study.

\section{Questionnaire development}

The questionnaire was developed on the basis of numerous literature reviews conducted by the investigators and was revised by five experts in oncologic nursing; it was also tested and showed a 95\% validity (Supplementary materials). Face validity considering the layout and structure of the KAP-related questionnaire was determined by the oncologists, research personnel, and statistician developing the questionnaire toward the daily management of PICC among patients with malignant tumor. Response rates for all test questions were evaluated to determine the poorly designed questions, which were eliminated from the final questionnaire and provide a measure of linguistic validity. The questionnaire included items related to patients' general and sociodemographic characteristics (gender, age, and so on), and the KAP-related items assessed the three dimensions of KAP. There were 27 items in total: nine assessed knowledge, ranging from the benefits of fisting exercises to catheter exfoliation; seven assessed attitudes toward learning PICC management and PICC management itself; and 11 assessed practices regarding how to care for the PICC in daily life. Scores were counted using 5-point Likert scales. Each patient participant was asked to read a series of statements and rate the degree to which they agreed with each statement using a 5-point Likert scale ranging from 1 (did not know at all or disagree) to 5 (know very well or agree strongly). The total points for all of the three domains of knowledge (nine items), attitude (seven items), and practice (11 items) were calculated for analysis. The questionnaire has been determined to be both a reliable and a valid tool for assessing PICC management in cancer patients. The internal consistency for the current sample as a whole was excellent (Cronbach's $\alpha=0.887$ ), and it ranged from good to excellent for the knowledge (Cronbach's $\alpha=0.807$ ), attitude (Cronbach's $\alpha=0.813$ ), and practice (Cronbach's $\alpha=0.809$ ) subscales. The data of the surveys were collected by patient self-reports. The diagnosis of the disease was confirmed by patient clinical and pathologic findings. 


\section{Statistical analyses}

Descriptive statistics were used to summarize patient characteristics as well as responses to items regarding patients' KAP toward PICC management. We used the Kolmogorov-Smirnov test to assess normality of each dataset. Continuous data were expressed as mean $\pm \mathrm{SD}$ and compared using independent-samples $t$-test for differences between demographic variables and the scores on the 5-point Likert scale for KAP. Otherwise they were expressed as median (interquartile range) if not normally distributed and compared using Mann-Whitney U-tests. Multivariate stepwise linear regression analysis was used to determine the relationships between participants' characteristics and the KAP score for PICC management. All statistical analyses were performed using SPSS version 21 (SPSS, Chicago, IL, USA), and statistical significance was defined as a $P$-value $<0.05$.

\section{Results}

\section{Patient characteristics}

Table 1 presents a summary of study patients' characteristics. In total, 155 questionnaires were collected from two hospitals. After excluding three questionnaires with incomplete responses, 152 questionnaires remained in the analysis. The patients' mean age was 49.3 years (range 20-79). The mean PICC indwelling time was 69.8 days (range 30-173). The total mean KAP score was $105.03 \pm 8.80$ points, and the standard score was $77.80 \pm 6.52$ points, among which the standard score for knowledge was the lowest $(72.47 \pm 8.44$ points) and the standard score for practice was the highest (80.56 \pm 7.23 points). Detailed clinical factors affecting patient scores on KAP toward the daily management of PICC are presented in Table 2.

\section{Knowledge toward the daily management of PICC}

The average score for knowledge of the daily management of PICC was $32.61 \pm 3.80$ points. The average standard score was $72.47 \pm 8.44$ points. The standard score was divided into nine items, in which the question on emergency treatment knowledge had the lowest score (5.29 \pm 1.35 points), while questions on the knowledge of PICC maintenance had the highest score ( $9.05 \pm 0.97$ points). The four knowledge items with the lowest scores are presented in Table S1.

\section{Attitude toward the daily management of PICC}

The PICC management attitudes questionnaires for patients with malignant tumors consisted of two parts: beliefs related
Table I Respondent characteristics of included patients

\begin{tabular}{|c|c|c|}
\hline Characteristics & Number of cases & $\%$ \\
\hline \multicolumn{3}{|l|}{ Gender } \\
\hline Male & 63 & 41.45 \\
\hline Female & 89 & 58.55 \\
\hline \multicolumn{3}{|l|}{ Age (years) } \\
\hline $20-39$ & 21 & 13.82 \\
\hline $40-59$ & 74 & 48.68 \\
\hline $60-79$ & 57 & 37.50 \\
\hline \multicolumn{3}{|l|}{ Educational degree } \\
\hline Junior high school or below & 65 & 42.76 \\
\hline High school or secondary school & 60 & 39.48 \\
\hline College or above & 27 & 17.76 \\
\hline \multicolumn{3}{|l|}{ Occupation } \\
\hline Worker & 14 & 9.21 \\
\hline Farmer & 56 & 36.84 \\
\hline Cadre & 41 & 26.97 \\
\hline Freelance & 39 & 25.66 \\
\hline Others & 2 & 1.32 \\
\hline \multicolumn{3}{|l|}{ Medical payment mode } \\
\hline Public medical care & 7 & 4.61 \\
\hline Health insurance & 76 & 50.00 \\
\hline Rural cooperative medical care & 58 & 38.16 \\
\hline Business insurance & 6 & 3.95 \\
\hline Self-paying medical services & 5 & 3.28 \\
\hline \multicolumn{3}{|l|}{ PICC indwelling time (days) } \\
\hline $30-89$ & 104 & 68.42 \\
\hline $90-179$ & 48 & 31.58 \\
\hline \multicolumn{3}{|l|}{ Current residence } \\
\hline Rural areas & 45 & 29.61 \\
\hline Nonrural areas & 107 & 70.39 \\
\hline \multicolumn{3}{|c|}{ Monthly per capita family income (Chinese yuan) } \\
\hline$<1000$ & 24 & 15.79 \\
\hline $1000-3000$ & 99 & 65.13 \\
\hline $3000-5000$ & 20 & 13.16 \\
\hline$>5000$ & 9 & 5.92 \\
\hline \multicolumn{3}{|l|}{ Cancer type } \\
\hline Head and neck cancer & 26 & 17.11 \\
\hline Lung cancer & 29 & 19.08 \\
\hline Gastrointestinal cancer & 31 & 20.39 \\
\hline Breast cancer & 20 & 13.16 \\
\hline Lymphoma & 24 & 15.79 \\
\hline Others & 22 & 14.47 \\
\hline \multicolumn{3}{|l|}{ Sepsis in ICU } \\
\hline Yes & 42 & 27.63 \\
\hline No & 110 & 72.37 \\
\hline \multicolumn{3}{|l|}{ Treated with mechanical ventilation } \\
\hline Yes & 78 & 51.32 \\
\hline No & 74 & 48.68 \\
\hline \multicolumn{3}{|l|}{ ICU length of stay, days } \\
\hline$>7$ days & 55 & 36.18 \\
\hline$<7$ days & 97 & 63.82 \\
\hline
\end{tabular}

Abbreviations: ICU, intensive care unit; PICC, peripherally inserted central catheter.

to daily management had a lower score ( $11.30 \pm 0.74$ points), and attitude toward emergency treatment had a higher score ( $16.82 \pm 0.56$ points). There were seven items related to attitude toward the daily management of PICC. Overall, $40.79 \%$ 
Table 2 Clinical factors affecting patient scores on knowledge, attitude, and practice toward the daily management of PICC

\begin{tabular}{|c|c|c|c|c|c|c|}
\hline Characteristics & $\begin{array}{l}\text { PICC } \\
\text { management } \\
\text { knowledge }\end{array}$ & $P$-value & $\begin{array}{l}\text { PICC } \\
\text { management } \\
\text { attitude }\end{array}$ & $P$-value & $\begin{array}{l}\text { PICC } \\
\text { management } \\
\text { practice }\end{array}$ & $P$-value \\
\hline Gender & & 0.141 & & 0.204 & & 0.192 \\
\hline Male & $32.12 \pm 3.53$ & & $27.76 \pm 3.53$ & & $43.85 \pm 3.59$ & \\
\hline Female & $33.04 \pm 3.99$ & & $28.42 \pm 3.08$ & & $44.70 \pm 4.27$ & \\
\hline Age (years) & & 0.019 & & 0.089 & & 0.015 \\
\hline $20-39$ & $34.29 \pm 4.01$ & & $29.52 \pm 3.54$ & & $110.43 \pm 9.35$ & \\
\hline $40-59$ & $32.85 \pm 3.86$ & & $27.92 \pm 3.38$ & & $104.70 \pm 9.67$ & \\
\hline $60-79$ & $31.68 \pm 3.42$ & & $27.84 \pm 2.65$ & & $103.47 \pm 6.64$ & \\
\hline Educational degree & & $<0.001$ & & $<0.001$ & & $<0.001$ \\
\hline Middle school or below & $31.12 \pm 3.40$ & & $27.46 \pm 2.92$ & & $43.08 \pm 3.36$ & \\
\hline High school/technical secondary school & $33.07 \pm 3.40$ & & $27.78 \pm 3.14$ & & $44.28 \pm 3.97$ & \\
\hline College and above & $35.19 \pm 4.00$ & & $30.40 \pm 2.94$ & & $47.33 \pm 3.86$ & \\
\hline Occupation & & $<0.001$ & & 0.002 & & $<0.001$ \\
\hline Worker & $32.07 \pm 4.16$ & & $28.43 \pm 3.13$ & & $43.43 \pm 3.96$ & \\
\hline Farmer & $31.01 \pm 3.25$ & & $26.84 \pm 2.69$ & & $42.66 \pm 3.39$ & \\
\hline Cadre & $33.63 \pm 3.51$ & & $29.34 \pm 3.05$ & & $46.02 \pm 3.67$ & \\
\hline Freelance & $34.13 \pm 3.89$ & & $28.56 \pm 3.47$ & & $45.23 \pm 4.20$ & \\
\hline Others & $30.50 \pm 3.54$ & & $27.50 \pm 3.54$ & & & \\
\hline PICC indwelling time & & 0.001 & & 0.005 & & 0.009 \\
\hline 30-89 days & $31.55 \pm 3.39$ & & $27.63 \pm 3.08$ & & $42.89 \pm 4.38$ & \\
\hline $90-179$ days & $34.92 \pm 3.63$ & & $29.19 \pm 3.40$ & & $44.49 \pm 3.79$ & \\
\hline Place of residence & & $<0.001$ & & $<0.001$ & & $<0.001$ \\
\hline Rural areas & $30.35 \pm 3.00$ & & $26.80 \pm 3.10$ & & $42.52 \pm 3.28$ & \\
\hline Nonrural areas & $33.86 \pm 3.62$ & & $28.84 \pm 3.00$ & & $45.30 \pm 4.00$ & \\
\hline Monthly per capita family income & & 0.388 & & 0.733 & & 0.063 \\
\hline \multicolumn{7}{|l|}{ (Chinese yuan) } \\
\hline$<1000$ & $32.80 \pm 3.38$ & & $27.76 \pm 3.33$ & & $43.28 \pm 3.10$ & \\
\hline $1000-3000$ & $32.23 \pm 3.79$ & & $28.01 \pm 3.20$ & & $44.26 \pm 4.08$ & \\
\hline $3000-5000$ & $33.67 \pm 4.17$ & & $28.67 \pm 2.88$ & & $45.93 \pm 4.03$ & \\
\hline$>5000$ & $32.70 \pm 3.80$ & & $28.40 \pm 3.69$ & & $43.00 \pm 3.88$ & \\
\hline
\end{tabular}

Note: Data are presented as means \pm SD.

Abbreviation: PICC, peripherally inserted central catheter.

of patients had a standard score $>80$, and $72.06 \%$ of patients had confidence in PICC management. Among them, the question referring to "the need for immediate treatment in case of abnormal PICC dressing" had the lowest score (3.60 \pm 0.71 points). The question that referred to patients' attitude toward the treatment of bleeding and exudate had the highest score (89.08 \pm 11.00 points). The four attitude items with the least scores are presented in Table S2.

\section{Practice toward the daily management of PICC}

The questionnaires on practice related to the daily management of PICC were divided into four parts including daily observation behavior (three items), daily life management (four items), engagement in exercise after indwelling PICC (three items), and timely maintenance (one item). Among them, timely maintenance had the best compliance and the highest standard score (90.13 \pm 10.29 points). Engagement in exercise after indwelling PICC had the worst compliance, with the lowest standard score (60.69 \pm 6.25 points). Among 152 patients, the average score was $44.31 \pm 3.98$ points and the standard score was $80.56 \pm 7.23$ points, $46.05 \%$ (70/152) of which had a standard score $>80$ points. Observation around the puncture site had the worst compliance, with an average score of $3.12 \pm 0.83$ points. The four practice items with the least scores are presented in Table S3.

\section{Factors affecting patients' KAP toward the daily management of PICC}

Here, the cumulative KAP score (the sum of scores of KAP) is the dependent variable. We conducted a multiple stepwise linear regression analysis using a single statistically 
significant factor derived from the univariate analysis of influencing factors that included the following: medical payment mode, educational degree, place of residence, occupation, PICC indwelling time, and patient age. The results of the multiple linear regression analysis showed that patient age, place of residence, PICC indwelling time, and educational degree influenced the total KAP score $(P<0.05)$. Among them, patient age was a negative factor in total KAP score, while place of residence, PICC indwelling time, and educational degree were positive factors for total KAP score (Table 3).

\section{Discussion}

This study demonstrated that KAP toward the daily management of PICC was at a medium level, which leaves room for improvement. The most influential factors in the PICC daily management total scores among cancer patients were patient age, place of residence, PICC indwelling time, and educational degree.

\section{Current situation regarding patient knowledge toward the daily management of PICC}

The standard scores for both the basic knowledge and the PICC indwelling precautions toward the daily management of PICC were $>80$ points each, while the standard scores for both emergency treatment knowledge and prevention knowledge were $<70$ points. This indicated that patients possessed a certain degree of PICC basic knowledge and precautions but lacked knowledge regarding emergency treatment and prevention; these findings were similar to those obtained by $\mathrm{Li}$ et al. ${ }^{13}$ These results are mostly due to the following reasons: the relatively low incidence of such emergency situations and the concomitant relative inattention paid to them by nurses and patients alike, the inadequate understanding of PICC- related complications, the lack of prevention knowledge, the nurses' insufficient knowledge of changes in foreign guidelines, and the difficulty in understanding the professional nursing skills required for PICC.

\section{Current situation regarding patient attitudes toward the daily management of PICC}

The standard score for patient attitudes toward the daily management of PICC was $80.32 \pm 9.09$ points, indicating that patients had a good attitude toward seeking medical treatment. However, when patients did not recognize the harmful factors, they lacked attitudes that favored the seeking of medical treatment. In our study, $40.79 \%$ of the patients had a standard score $>80$, while $49.70 \%$ of the patients would take the initiative to learn PICC-related knowledge, indicating that the attitude of cancer patients was above the middle level. Nevertheless, $72.06 \%$ of the cancer patients were confident in the daily management of PICC, which was consistent with the findings by Wei et a $1^{14}$ but lower than the level reported by Zhang et al. ${ }^{15}$

\section{Current situation regarding patient practices toward the daily management of PICC}

The standard score for patient practice toward the daily management of PICC was $80.56 \pm 7.23$ points, ranging from $62.37 \pm 16.59$ to $90.13 \pm 10.29$ points among the items, indicating that the patients' health behavior was not uniform, with a wide range of fluctuations in compliance, and that targeted health education is required. The standard scores for daily management and timely maintenance of PICC were both $>80$ points, while the standard scores for daily observation and engagement in exercise after indwelling PICC were both $>70$ points, indicating that the patients had good behavioral

Table 3 Results of multiple stepwise linear regression analysis of factors influencing patient knowledge, attitude, and practice toward the daily management of PICC

\begin{tabular}{|c|c|c|c|c|c|}
\hline Independent variables & $\begin{array}{l}\text { Regression } \\
\text { coefficient } \beta\end{array}$ & $\begin{array}{l}\text { Standard } \\
\text { error }\end{array}$ & $\begin{array}{l}\text { Standardized } \\
\text { regression } \\
\text { coefficient } \beta\end{array}$ & $t$ & P-value \\
\hline Constant term & 87.054 & 5.081 & - & 16.644 & $<0.001$ \\
\hline Place of residence & 4.494 & 1.689 & 0.245 & 2.661 & 0.009 \\
\hline Occupation & 1.195 & 0.642 & 0.134 & 1.863 & 0.064 \\
\hline Age & -1.980 & 0.866 & -0.153 & -2.286 & 0.024 \\
\hline Educational degree & 3.225 & 0.862 & 0.271 & 3.743 & $<0.001$ \\
\hline PICC indwelling time & 4.513 & 1.265 & 0.239 & 3.569 & $<0.001$ \\
\hline
\end{tabular}

Abbreviation: PICC, peripherally inserted central catheter. 
compliance with respect to daily management and timely maintenance but had poor compliance with daily observation and exercise after indwelling PICC. We found that only $32.89 \%$ of the patients observed the puncture site every day, and $49.34 \%$ of the patients would observe the PICC on their own, which was similar to previous findings. ${ }^{16}$

\section{The factors influencing KAP toward the daily management of PICC among cancer patients}

The results of the present study indicate that educational level is one factor influencing KAP score toward the daily management of PICC. Patients with a higher education level had higher total scores for KAP than those with a lower education level, which was similar to the results reported by Peng et al. ${ }^{17}$ Patients with a higher education level had a broader knowledge base relevant to the daily management of PICC and could easily understand the necessity for PICC management. This understanding led to the formation of positive and healthy beliefs that could ultimately facilitate the emergence of healthy behaviors. Conversely, the formation of healthy behaviors among patients with a lower education level was limited. The total KAP scores for patients living in rural areas were lower than those in nonrural areas, which was consistent with findings by Liu et al. ${ }^{18}$

This study showed that the longer the indwelling time was, the higher the total KAP score was. This might be due to patients' gradual understanding of the benefits of PICC with prolonged periods of having an indwelling PICC. Consequently, they would generate positive beliefs and start taking the initiative to learn PICC-related knowledge.

The study showed that age was a limiting factor for KAP total score. The patients ranging from 20 to 39 years of age had the highest KAP total scores, while those from 60 to 79 years of age had the lowest total scores. This could be related to decreased organ functions related to perception, memory, and thinking ${ }^{19}$ and to the fact that elderly patients are not generally interested in participating in the treatment of disease..$^{20}$

This study is the first one to utilize the questionnaire of KAP score to assess the daily management of PICC in critically ill cancer patients discharged from ICUs. Up till now, we have found no similar reports regarding this topic. Despite the strengths, several limitations should also be addressed; for example, we used the convenient samples and patient self-reported surveys, which might have brought about bias to some extent.

\section{Conclusion}

The total KAP score was influenced by factors such as patient age, place of residence, PICC indwelling time, and educational degree, which should be improved. Improvements in KAP score are ultimately the responsibility of health education, a means of disseminating health knowledge through education and intervention to promote the formation of positive attitudes and beliefs, thereby changing adverse behaviors and establishing healthy ones. Therefore, in clinics, more attention should be paid to the role of knowledge and attitude on behavior change as well as its influential factors, thus reducing the complications of PICC and improving patients' quality of life. We proposed that large prospective clinical study should be designed and more subgroup analyses could be conducted based on those investigated influencing factors of KAP status to better understand its effect.

\section{Acknowledgment}

This research was supported by the National Natural Science Foundation of China (grant no. 81701843).

\section{Disclosure}

The authors report no conflicts of interest in this work.

\section{References}

1. Bortolussi R, Zotti P, Conte M, et al. Quality of life, pain perception, and distress correlated to ultrasound-guided peripherally inserted central venous catheters in palliative care patients in a home or hospice setting. J Pain Symptom Manage. 2015;50(1):118-223.

2. Molloy D, Smith L, Aitchison T. Cytotoxic chemotherapy for incurable colorectal cancer: living with a PICC-line. J Clin Nurs. 2008;17(18):2398-2407.

3. Parás-Bravo P, Paz-Zulueta M, Santibañez M, et al. Living with a peripherally inserted central catheter: the perspective of cancer outpatients-a qualitative study. Support Care Cancer. 2017;26(2):441-449.

4. Kramer R, Rogers M, Conte M, Mann J, Saint S, Chopra V. Are antimicrobial peripherally inserted central catheters associated with reduction in central line-associated bloodstream infection? A systematic review and meta-analysis. Am J Infect Control. 2017;45(2):108-114.

5. Pittiruti M, Brutti A, Celentano D, et al. Clinical experience with powerinjectable PICCs in intensive care patients. Crit Care. 2012;16(1):R21.

6. Yamaguchi R, Noritomi D, Degaspare N, et al. Peripherally inserted central catheters are associated with lower risk of bloodstream infection compared with central venous catheters in paediatric intensive care patients: a propensity-adjusted analysis. Intensive Care Med. 2017;43(8):1097-1104.

7. Cotogni P, Pittiruti M. Focus on peripherally inserted central catheters in critically ill patients. World J Crit Care Med. 2014;3(4):80-94.

8. Orme R, McSwiney M, Chamberlain-Webber R. Fatal cardiac tamponade as a result of a peripherally inserted central venous catheter: a case report and review of the literature. Br J Anaesth. 2007;99(3):384-388.

9. Venkatesan T, Sen N, Korula P, et al. Blind placements of peripherally inserted antecubital central catheters: initial catheter tip position in relation to carina. Br J Anaesth. 2007;98(1):83-88.

10. Khorana A, Fine R. Pancreatic cancer and thromboembolic disease. Lancet Oncol. 2004;5(11):655-663. 
11. Pongruangporn M, Ajenjo M, Russo A, et al. Patient- and devicespecific risk factors for peripherally inserted central venous catheterrelated bloodstream infections. Infect Control Hosp Epidemiol. 2013;34(2):184-189.

12. Pei C. Experience in the centralized management of patients with PICC. J Nurs Adm. 2009;(4):51-52.

13. Li S, Chen W, Chen Q, Yang Y. Effect of cognitive intervention on selfprotection ability and health knowledge for cancer patients indwelling with PICC. Chin J Pract Nurs. 2012;10(35):3308-3309.

14. Wei H, Zhao Q. The knowledge-attitude-practice on catheter maintenance in outpatients with peripherally inserted central catheter. Chin Nurs Manag. 2014;(5):472-475.

15. Zhang X, Liao J. Influence of enhanced patient education on the patients' knowledge and awareness of peripherally inserted central catheter. Chin J Clin Nutr. 2013;21(5):313-315.
16. Zhang D, Wang S, Wang X, Han B. Investigation and research of self-care staus-quo in PICC patient. Nurse Practice and Research. 2011;8(2):101-103.

17. Peng N, Jiang X. Influencing factors and countermeasures of the adherence of PICC discharged from hospital. Journal of Guiyang College of Traditional Chinese Medicine. 2014;36(4):140-142.

18. Liu C, MQY, Lu Z, Zhao M. Investigation on self-management capability among cancer patients with PICC and its influencing factors. Chin J Nurs Educ. 2011;8(7):294-297.

19. Zhang Q, Zeng H, Song L. Impact of cognitive training on cognitive function in aged community residents. Int J Nurs Sci. 2010;(2):16-18.

20. Longtin Y, Sax H, Leape L, Sheridan S, Donaldson L, Pittet D. Patient participation: current knowledge and applicability to patient safety. Mayo Clin Proc. 2010;85(1):53-62. 


\section{Supplementary materials}

PART ONE: General and sociodemographic characteristics of the respondents

Date:

1. Code of the respondent

2. Gender: A. Male B. Female

3. Age (year):

4. What is your PICC indwelling time:

5. What type of disease do you have:

6. What is your current residence?
A. Rural area
B. Nonrural area

7. What is your career?
A. Worker
B. Farmer
C. Cadre
D. Freelance
E. Other

8. What is your monthly per capita family income (Chinese yuan)?
A. $<1000$
B. $1000-3000$
C. $3000-5000$
D. $>5000$

9. What is your educational degree?
A. Junior high school or below
B. High school or secondary school
C. College or above

PART TWO: Items related to knowledge, attitude, and practice toward the daily management of PICC No. 1. Do you know you can elevate your indwelling arm when you sleep?
A. Did not know at all
B. Do not know well
C. A general knowledge
D. Know well
E. Know very well

No. 2. Do you know that your indwelling arm cannot be pressed when you sleep?
A. Did not know at all
B. Do not know well
C. A general knowledge
D. Know well
E. Know very well

No. 3. Do you know that silk stockings and sleeves can provide a protective effect on PICC?
A. Did not know at all
B. Do not know well
C. A general knowledge
D. Know well
E. Know very well

No. 4. Do you know that your indwelling arm cannot engage in strenuous exercises?
A. Did not know at all
B. Do not know well
C. A general knowledge
D. Know well
E. Know very well

No. 5. Do you know swimming or bathing is forbidden after PICC indwelling?
A. Did not know at all
B. Do not know well
C. A general knowledge
D. Know well
E. Know very well

No. 6. Do you know that changing the PICC indwelling needle foil, changing the dressing, and flushing in time can protect against infection and tube blocking?
A. Did not know at all
B. Do not know well
C. A general knowledge
D. Know well
E. Know very well

No. 7. Do you know that fisting exercise can prevent PICC indwelling-related complications?
A. Did not know at all
B. Do not know well
C. A general knowledge
D. Know well
E. Know very well

No. 8. Do you know that when PICC fracture occurs, the upper indwelling arm should be bandaged before hospitalization treatment?
A. Did not know at all
B. Do not know well
C. A general knowledge
D. Know well
E. Know very well

No. 9. Do you know that the prolapsed indwelling PICC catheter should not be inserted into the blood vessel again?
A. Did not know at all
B. Do not know well
C. A general knowledge
D. Know well
E. Know very well

No. 10. Will you take the initiative to learn the knowledge related to PICC self-management?
A. Strongly disagree
B. Disagree
C. Neither agree nor disagree
D. Agree
E. Strongly agree

No. 11. Do you think that PICC self-management in daily life is very important?
A. Strongly disagree
B. Disagree
C. Neither agree nor disagree
D. Agree
E. Strongly agree

No. 12. Do you have full confidence in PICC self-management after discharge from the hospital?
A. Strongly disagree
B. Disagree
C. Neither agree nor disagree
D. Agree
E. Strongly agree

No. 13. Will you go to the hospital immediately to change the PICC dressing during inversion, looseness, or dampness?
A. Strongly disagree
B. Disagree
C. Neither agree nor disagree
D. Agree
E. Strongly agree 
No. 14. Will you go to the hospital immediately once complications such as oozing, bleeding, redness, swelling, heat, and pain occur around the puncture site?
A. Strongly disagree
B. Disagree
C. Neither agree nor disagree
D. Agree
E. Strongly agree

No. 15. Will you go to the hospital immediately when there is blood return in the PICC?
A. Strongly disagree
B. Disagree
C. Neither agree nor disagree
D. Agree
E. Strongly agree

No. 16. Will you go to the hospital for treatment when swelling of the indwelling arm occurs?
A. Strongly disagree
B. Disagree
C. Neither agree nor disagree
D. Agree
E. Strongly agree

No. 17. Will you monitor to see if the PICC is broken or if blood returns in the PICC?
A. Strongly disagree
B. Disagree
C. Neither agree nor disagree
D. Agree
E. Strongly agree

No. 18. Will you measure the PICC arm circumference every day?
A. Strongly disagree
B. Disagree
C. Neither agree nor disagree
D. Agree
E. Strongly agree

No. 19. Will you monitor for oozing, bleeding, redness, swelling, heat, and pain around the puncture site?
A. Strongly disagree
B. Disagree
C. Neither agree nor disagree
D. Agree
E. Strongly agree

No. 20. Will you lift something heavier than 3 kilograms with your PICC indwelling arm?
A. Strongly disagree
B. Disagree
C. Neither agree nor disagree
D. Agree
E. Strongly agree

No. 21. Will you protect the puncture site with a preservative film or waterproof gloves when swimming?
A. Strongly disagree
B. Disagree
C. Neither agree nor disagree
D. Agree
E. Strongly agree

No. 22. Will you dress the PICC indwelling arm first and undress it last?
A. Strongly disagree
B. Disagree
C. Neither agree nor disagree
D. Agree
E. Strongly agree

No. 23. Will you press the PICC indwelling arm at sleep?
A. Strongly disagree
B. Disagree
C. Neither agree nor disagree
D. Agree
E. Strongly agree

No. 24. Will you engage in strenuous exercise after receiving an indwelling PICC?
A. Strongly disagree
B. Disagree
C. Neither agree nor disagree
D. Agree
E. Strongly agree

No. 25. Will you hold on to the bus/subway rings for a long time with your PICC indwelling arm when you ride a bus/subway without a seat?
A. Strongly disagree
B. Disagree
C. Neither agree nor disagree
D. Agree
E. Strongly agree

No. 26. Will you do fisting exercises for the PICC indwelling arm every day?
A. Strongly disagree
B. Disagree
C. Neither agree nor disagree
D. Agree
E. Strongly agree

No. 27. Will you conduct PICC maintenance at your regular hospital every week?
A. Strongly disagree
B. Disagree
C. Neither agree nor disagree
D. Agree
E. Strongly agree

Thank you very much for participating in my survey!!

Figure SI Questionnaire for the assessment of knowledge, attitude, and practice toward the daily management of PICC among patients with malignant tumor. Abbreviation: PICC, peripherally inserted central catheter.

Table SI The four knowledge items with the lowest scores

\begin{tabular}{lllll}
\hline Item numbers & Min & Max & Average score $(\overline{\mathbf{x}} \pm \mathbf{s})$ & Standard score $(\overline{\mathbf{x}} \pm \mathbf{s})$ \\
\hline 8 & 1 & 5 & $2.14 \pm 0.71$ & $42.76 \pm 14.20$ \\
1 & 2 & 5 & $2.70 \pm 0.71$ & $53.95 \pm 14.19$ \\
4 & 1 & 5 & $3.10 \pm 0.81$ & $61.97 \pm 16.24$ \\
9 & 1 & 5 & $3.15 \pm 0.83$ & $63.03 \pm 16.56$ \\
\hline
\end{tabular}

Abbreviations: Max, maximal value; Min, minimal value.

Table S2 The four attitude items with the lowest scores

\begin{tabular}{lllll}
\hline Item numbers & Min & Max & Average score $(\bar{x} \pm s)$ & Standard score $(\bar{x} \pm s)$ \\
\hline 10 & 2 & 5 & $3.65 \pm 0.76$ & $73.01 \pm 15.23$ \\
11 & 2 & 5 & $3.86 \pm 0.76$ & $77.21 \pm 15.24$ \\
12 & 2 & 5 & $3.79 \pm 0.66$ & $75.79 \pm 13.54$ \\
13 & 2 & 5 & $3.60 \pm 0.71$ & $71.97 \pm 14.24$ \\
\hline
\end{tabular}

Abbreviations: Max, maximal value; Min, minimal value. 
Table S3 The four practice items with the lowest scores

\begin{tabular}{lllll}
\hline Item numbers & Min & Max & Average score $(\overline{\mathbf{x}} \pm \mathbf{s})$ & Standard score $(\overline{\mathbf{x}} \pm \mathbf{s})$ \\
\hline 18 & 2 & 5 & $3.57 \pm 0.67$ & $71.44 \pm 13.54$ \\
19 & 2 & 5 & $3.12 \pm 0.83$ & $62.37 \pm 16.59$ \\
25 & 3 & 5 & $3.89 \pm 0.60$ & $77.89 \pm 11.99$ \\
26 & 3 & 5 & $3.74 \pm 0.58$ & $74.74 \pm 11.68$ \\
\hline
\end{tabular}

Abbreviations: Max, maximal value; Min, minimal value.

\section{Publish your work in this journal}

Cancer Management and Research is an international, peer-reviewed open access journal focusing on cancer research and the optimal use of preventative and integrated treatment interventions to achieve improved outcomes, enhanced survival and quality of life for the cancer patient. The manuscript management system is completely online and includes a very quick and fair peer-review system, which is all easy to use. Visit http://www.dovepress.com/testimonials.php to read real quotes from published authors.

Submit your manuscript here: https://www.dovepress.com/cancer-management-and-research-journal 